\title{
THE USE OF DEVELOPMENTAL EDUCATIONAL TECHNOLOGIES IN ACTIVATING THE COGNITIVE PROCESS OF CHILDREN
}

\section{Saidova D.I.}

Associate Professors, Department Of Pedagogy And Psychology, Institute For Retraining And Advanced Training Of Managers And Specialists Of Preschool Educational Institutions, Uzbekistan

ABSTRACT

The article examines the role of educational technologies and their effectiveness in accelerating the reform of the preschool education system and the development of the child's educational process. The views on the systemic implementation of developing educational technology and its principles in organizations of preschool education are reflected.

KEYWORDS:- Developmental education, teacher, method, method, structure, cognitive competence, flexibility, creativity.

\section{INTRODUCTION}

Attention to the upbringing of the younger generation is one of the most pressing issues in our country. Because the development and future of the country is provided by the youth, they are responsible for the future of the country not only as the successors of the development relay of the country, but also as the creators and creators. Based on this, it is necessary to develop the national consciousness and moral qualities of the younger generation, to cultivate in them an advanced scientific worldview, ideological conviction, deep knowledge and diligence.

To be effective in any educational play activity, it is important to focus on the unity of education and upbringing. Because the unity of education and upbringing in the classroom are always concepts that require one another. Some educators focus on education only in educational play activities, forgetting to form competencies, which should focus on the process of applying it in practice, strengthening the theoretical knowledge of the subject, replacing the specific features of the complex, the basic elements. However, the goal cannot be achieved if the lesson focuses on the educational aspects of the topic and ignores the educational or developmental aspects. The importance of developmental learning technologies in the preschool education process is great. In order to raise pre-school education to the level of the foundation of knowledge, it is necessary to use a combination of different modern pedagogical technologies, methods and techniques, i.e. interactive methods. In addition to the educational nature of each educational play activity, the educator's work in accordance with the theme forms in children active movement, independent thinking skills.

\section{THE MAIN FINDINGS AND RESULTS}


The child does not fully understand the lesson, does not understand its essence, does not recognize the purpose of the lesson, performs the tasks given by the educator only on the basis of obligation. This in itself dampens the child's interest in learning. With this in mind, it is important to allow the child to defend his or her views. Because the intensive development, enlightenment and spiritual development of the child is directly due to the activities of his teacher. Another important thing in preschool education is that the child's psyche, the uniqueness of his inner world should always be in the focus of the educator. Individual aspects of preschool education are manifested and knowledge is subjected. Because traditional teaching methods provided knowledge in a ready-made way, it was difficult for children to apply it in practice. In particular, in preschool education, children did not develop independent thinking skills due to the fact that they were limited in their ability to think independently on the topic only under the guidance of a teacher. This, in turn, created difficulties in finding solutions to some complex problems in children's future lives.

Modern pedagogical technologies allow to study the topic of each educational game activity on the basis of the principle of integrity, based on the content and characteristics of preschool education, as the main goals and objectives of the lesson, and to apply research methods accordingly. In turn, the main purpose of preschool education is to teach children to master the basics of knowledge, to develop scientific thinking, ability, speech and independent thinking, as well as to understand the opinions of others. Based on this, to develop children's thinking potential, mental development, logical thinking; it opens the way to self-understanding, to a material being in a peculiar way, and to the ability to express one's thoughts and feelings beautifully, to apply knowledge in practice.

The active application of modern pedagogical technologies is important in the development of children's cognitive competencies in the process of preschool education. The acquisition of knowledge, skills and competencies requires the direct involvement of children and the use of management-based pedagogical technology by educators. An important aspect of the application of modern pedagogical technologies in the educational process is that children become equal members of the educational process. The choice of types of modern pedagogical technologies depends on the emerging knowledge, skills and abilities, the form of organized lessons, the nature of the methods used and methodological methods.

An approach based on modern pedagogical technologies, the rational use of developmental educational technologies in the educational process play an important role in the lessons of preschool education. The way in which children complete assignments in certain life situations, how they stop, and at what level they complete the tasks they are assigned, depend in many ways on preschool education. In preschool education, educators need to approach their work from the same perspective. To take into account the fact that modern pedagogical technologies used in preschool education create a strong need for children of all ages to express their opinions, to express their views independently; therefore, it is advisable to allow each child who reads the text to have his or her own point of view, without giving ready-made interpretations of the information in preschool education.

Preschool education development education focuses on developing children's academic knowledge as well as life skills, increasing their internal capacity, and realizing them [1, p. 50]. In this training, more trainings and presentations 
are used. The trainings help children to master certain knowledge, to form skills to apply them effectively in practice, and in the process to realize their full potential. This process is a conducive environment based on mutual respect and support directly between the child and the educator. At the same time, it is necessary to understand and take into account the life experience of each child, taking into account the uniqueness and importance of his inner world. The method is also based on helping children to develop their abilities in a way that believes in their goals, potential and future abilities, strengthens children's self-confidence, increases their cognitive activity, helps them to develop self-study and independent learning skills. It is aimed at increasing the inner potential of children and their realization. In this training, more trainings and presentations are used. The trainings help children to master certain knowledge, to form skills to apply them effectively in practice, and in the process to realize their full potential. This method helps students to develop a creative approach to the organization of educational activities, self-study, independent learning. It is aimed at increasing the inner potential of children and their realization. In this training, more trainings and presentations are used. The trainings help children to master certain knowledge, to form skills to apply them effectively in practice, and in the process to realize their full potential. This method helps students to develop a creative approach to the organization of educational activities, self-study, independent learning.

Guiding principles of developmental education technology:

Incorporation (systemic activity) - generalization of preschool theoretical knowledge through scientific analysis in terms of preschool education;

Flexibility - the application of the form, method and methods of teaching the subject in different educational institutions;

Harmony - to carry out the content in harmony with the forms, methods and techniques of personal development;

Creativity is a science in the process of preschool education, as well opportunities for teachers of various educational institutions to create innovative technologies, depending on the content, essence of the studied topic and the age characteristics of children;

Relying on naturalness is to take into account the specific, personal characteristics of children in accordance with genetic and social aspects [2].

All of the above embody the interrelated trinity in the educational process - education, upbringing and personal development, which is directly in line with the requirements of the Law on Education and the National Training Program.

Harmony - to carry out the content in harmony with the forms, methods and techniques of personal development;

Relying on naturalness is to take into account the specific, personal characteristics of children in accordance with genetic and social aspects [2].

All of the above embody the interrelated trinity in the educational process - education, upbringing and personal development, which is directly in line with the requirements of the Law on Education and the National Training Program.

Preschool educators need to approach their work from the same perspective. It is advisable to take into account the fact that innovations in preschool education create a strong need for children of all ages to express their opinions, to express their views independently, so that in preschool education materials are not ready, but allow each child to have their own point of view.

One of the most effective ways to develop developmental learning technology in preschool 
education is to systematically analyze topics. This is because systematic analysis is noteworthy in that it incorporates all the principles of developmental learning technology as it is focused on achieving a specific goal and task as a practical activity. In this sense, the main purpose of systematic analysis is to form personality traits in children through the correct perception of the subject. Its main task is to form in the child a sensitive heart, sensitive emotions, healthy aesthetic taste, fluent and expressive speech [3]. It is necessary to rely on the principle of structure in the implementation of these goals and objectives. This principle can be used in all classes in preschool education. A systematic approach to the process of preschool education should pay special attention to the intellectual potential, psycho-physiological state of children [4].

It should be noted that it is no secret that the use of developmental educational technologies in preschool education varies from time to time according to the level, taste, intellectual level of children.

With this in mind, the use of developmental educational technologies in preschool education should be based on the principle of systematic and pedagogical orientation, taking into account the intellectual potential and aesthetic thinking of children. Given the important role of preschool education in the development of a harmoniously developed person, the purification of human spirituality, the rational use of developmental educational technology in educational play activities is one of the important tasks of today.

\section{Conclusion}

From the above, it is clear that adherence to the principles of developmental education technology in preschool education increases the effectiveness of education, provides children with intellectual and moral qualities, the formation of personal life experiences and ensures the balanced implementation of educational and developmental goals in preschool education.

\section{ReFERENCES}

1. Xoshimova M.K. (2012) Pedagogical technologies and pedagogical skills. (Text of lectures). - Tashkent: TSIF. - p. 50.

2. Tolipov O., Usmonbekova M. (2006) Applied bases of pedagogical technologies. Tashken: Fan.

3. National Idea: Propaganda Technologies and Glossary of Terms. - Tashkent: Akademiya Publishing House. 2007.

4. "First step" State program of preschool education. - Tashkent: 2018.

5. Ismatullayeva, N. R. (2021). On the Introduction of E-Learning Portfolio in the Educational Process. Current Research Journal of Pedagogics (2767-3278), 2(09), 35-37.

6. Shomirzayev, M. K. (2021). Practical lessons in technology: Characteristics of organization and conduct. ASIAN JOURNAL OF MULTIDIMENSIONAL RESEARCH, 10(4), 991-1001. 